\title{
ERRATUM
}

Kwang-Baek Kim • Sungshin Kim • Gwang-Ha Kim

\section{Vector quantizer of medical image using wavelet transform and enhanced SOM algorithm}

Published online: 21 April 2006

(C) Springer-Verlag London Limited 2006

\section{Neural Comput \& Applic (2006) \\ DOI 10.1007/s00521-006-0026-1}

After the article had been published online, the author realized that better images of Figs. $7 \mathrm{~b}$ and $10 \mathrm{a}$ were necessary. These new images are shown below:
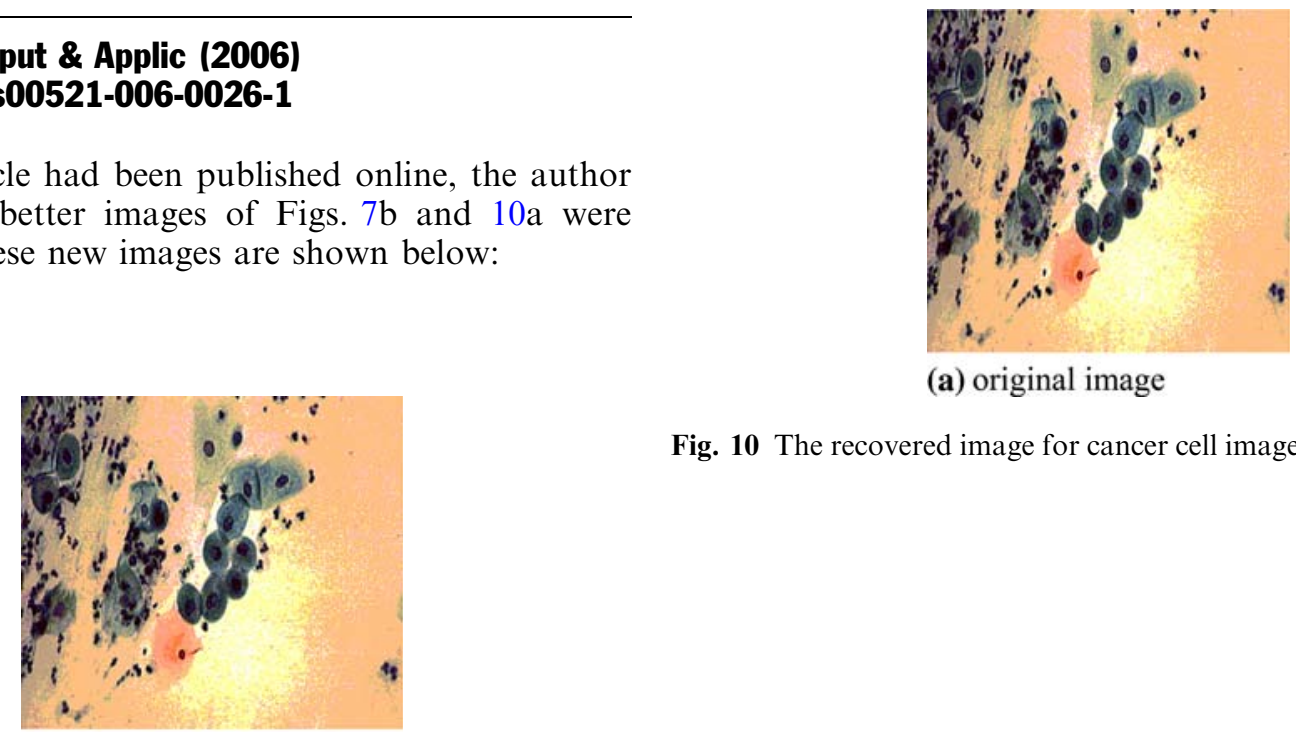

(a) original image

Fig. 10 The recovered image for cancer cell image: a original image

(b) Cancer image

Fig. 7 Medical image samples used for experimentation: $\mathbf{b}$ cancer image

The online version of the original article can be found at http:// www.doi.org/10.1007/s00521-006-0026-1

K.-B. Kim (ه)

Department of Computer Engineering, Silla University,

Busan, South Korea

E-mail: gbkim@silla.ac.kr

S. Kim

Department of Electrical Engineering, Pusan National University, Busan, South Korea

G.-H. Kim

Department of Internal Medicine,

Pusan National University College of Medicine,

Busan, South Korea 